\title{
Effects and Hazards of Drilling Fluids on Well Drilling Workers and the Administrative Processes Adopted in Iraqi Fields
}

\author{
Wisam Hussain \\ Baghdad Oil Training Institute (BOIT)
}

\section{Abstract}

Drilling fluids are any fluids which are circulated through a well while drilling in order to remove cuttings from a wellbore. During drilling, large volumes of fluids are circulating through the well and into open, partially enclosed or completely enclosed systems at high temperatures. When these drilling fluids are agitated during a circulating process there is significant potential for chemical exposure to workers and subsequent health effects. This study seeks to identify major areas of exposure to drilling fluids and the health hazards associated with the use of drilling fluids. The study also presents some challenges in setting the standards of exposure to the drilling fluids which have always not been given the same attention or concern as the effects and risk management of drilling fluids. Some exposure indicators are also presented.

Questionnaire has been done on seven Iraqi fields (Nahran Omar,Nasiriya ,Zubair,East Baghdad, North Rumaila, Humrain and Jambur ) to determine the administrative and protective processes adopted by our national companies in order to minimize the drilling fluid exposures. The questionnaire has been done also to get know the most important conclusions and use the reliable recommendations that achieve the research objective.

According to the data obtained from the questionnaire, there are no clear, standard and unique administrative and protective processes adopted by Iraqi drilling company in different sites. The study recommended the necessity of evaluating their processes related with reducing the risks of drilling fluid exposures and establishing a specialized committee to develop such drilling fluid systems.

Keywords: Drilling fluids, hazards, exposures, worker exposures, environmental considerations, management. 


\section{Introduction}

Drilling fluids are used extensively in the upstream oil and gas industry. When deciding a type of drilling fluid system to use, operator well planners have to conduct comprehensive risk assessments of drilling fluid systems by considering health aspects in addition to environmental and safety aspects. The results of these risk assessments must be available to all employers whose may become exposed to the drilling fluid system. This work provides a general background on drilling fluids and the various categories of base fluids and additives currently in use. It outlines potential health hazards associated with these substances, looks at opportunities for human exposure presented by drilling operations, and introduces risk management methods and monitoring processes to reduce the risk of harmful health effects. This guidance is evidencebased and aims to define and discuss best practices for reducing exposures and subsequent health effects through a risk-based management process. The document is designed to be used by operator and drilling personnel, managers, Health, Safety and Environment (HSE)managers, drilling fluid specialists, rig-site medical staff, and occupational health and hygiene profession(1).

\section{Drilling fluids and their functions}

Drilling fluids are a key requirement in the vast majority of drilling operations. The main functions performed by drilling fluids are to (1):

1- Provide a barrier for well control.

2- Remove cuttings from the wellbore as they are produced.

3- Maintain drill cuttings in suspension when drilling circulation is stopped.

4- Transmit hydraulic power to the drilling bit.

5- Maintain formation stability.

6- Maintain pressure on the formation.

7- Control fluid loss through filtration.

8- Cool and lubricate the drill bit and string.

9- Facilitate data logging-drilling fluids characteristics need to be controlled so that logging instruments can provide accurate information about the well and formations being drilled. 


\section{Types of drilling fluids}

According to OGP $(2,3)$, there are two main types of drilling fluids: Water Based Fluids (WBFs) and Non-Aqueous Drilling Fluids (NADFs) or Non-Aqueous base Fluid (NABFs).

1-Water Based Fluids (WBFs): WBFs consist of water mixed with bentonite, clay and barium sulphate (Barite) to control mud density and thus, hydrostatic head. Other substances are added to gain the desired drilling properties. These additives include thinners (e.g., lignosulphonate, or anionic polymers), filtration control agents (polymers such as carboxyl methyl cellulose or starch), lubrication agents (e.g., polyglycols) and numerous other compounds for specific functions (4).

2-Non-Aqueous Drilling Fluids (NADFs): NADFs are emulsions where the continuous phase is the Non-Aqueous Base Fluid (NABF) with water and chemicals as the internal phase. The NADFs comprise all non-water and non-water dispersible base fluids. Similar to WBFs, additives are used to control the properties of NADFs. Emulsifiers are used in NADFs to stabilize the water-in oil emulsions. Non-aqueous drilling fluid can further be subdivided into the following:-

Group I: high-aromatic content fluids. This category includes crude oil, diesel and conventional mineral oils. These fluids are refined from crude oil and contain levels of total aromatics between 5 and $35 \%$.

Group II: moderate-aromatic content fluids. This category contains products produced from crude oil with levels of total aromatics between 0.5 and $5 \%$ and is often known as 'low toxicity mineral oil' like lubricants.

Group III: low/negligible-aromatic content fluids. This group includes fluids produced by chemical reactions and highly refined mineral oils which contain levels of total aromatics below $0.5 \%$ and polycyclic aromatic hydrocarbon (PAH) levels below $0.001 \%$, according to the OGP definition (5). 


\section{Field findings}

Workers mostly affected by drilling exposure include the following: (4)

1-Floor and Derrick men: These people make pipe connection during tripping activities from the drill neck, collect cores and cutting samples and also perform the general housekeeping. They are also responsible for mixing and adding chemicals to the drilling fluid, collecting samples and monitor pumps.

2-Mud engineer: Mud engineer may periodically check the mud by measuring its viscosity, density and other properties.

\section{3-Laboratory}

During drilling, the drilling fluid is tested or checked by the mud engineer many times each day. This process requires sampling from a pit or flow line and uses various forms of testing equipment to gain the necessary information about the fluid for analysis and remedial treatment purposes. Some regulations require the use of fume hoods and extract ventilation systems in the fluids testing laboratory. More recent projects are concerned with the development of drilling fluids testing apparatus. The benefit of this development will eliminate personal contact with the respective fluids systems when testing for the fluids characteristics. Potential exposure when testing is more likely to be by skin contact than by inhalation. Due to the very limited quantities of drilling fluids and the controlled conditions which are typically involved in testing procedures extract ventilation systems are recommended (1).

4-Motor Man: People responsible for all the motors, generators and general maintenance of equipment at the working area (4).

\section{Major areas of drilling fluid exposure}

Exposures are mostly encountered in a typical drilling environment during drilling operation. The following areas were identified during the study as the major areas of drilling fluid exposure:

1- Shale shaker house.

2- Drilling floor.

3- Mud pit system.

4- Sack room.

5- Laundry services.

1-Shale shaker house: Workers may be exposed to drilling fluids either by inhaling aerosols and vapors/mist or by skin contact Figure (1). Other form of major exposure opportunities identified 
includes:

A- Washing shale shaker with high-pressure guns using a hydrocarbon-based fluid.

B- Cleaning and changing shale shaker screens.

C- Checking the shaker screens for wears.

D- Solid and Liquid separation.

E- Mechanical agitation of the Shale shaker (4).

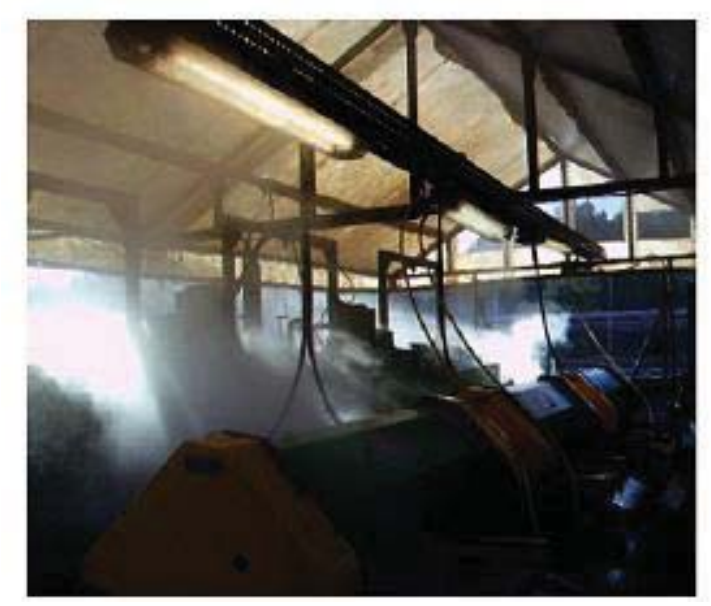

Fig. (1) Aerosol and vapor/mist exposure at shale shaker house (4)

2-Drilling floor: Contact with drilling fluids as well as lubricants, pipe dope, hydraulic oils, etc. by personnel on the drill floor is predominantly dermal contact. This can be prolonged and repetitive due to the manual nature of the work involved. In most cases contact may be through manual handling of unclean pipes during breaking out of pipes, preparing to break out pipes, handling of tubular, lowering of drill pipe, sprays, and spills from cleaning operations and high pressure washing(1).

3-Mud pit system: Mud is monitored throughout the drilling process. A mud engineer and/or the mud engineer may periodically check the mud by measuring its viscosity, density, and other properties. The mud engineer can be exposed to burns, or physical injury caused by contact with skin or eyes. Persons in the area are generally need to perform less complicated tasks but on regular basis with the potential of inhalation hazard and also explosions or violent reactions from chemical mixed improperly Figure (2). 


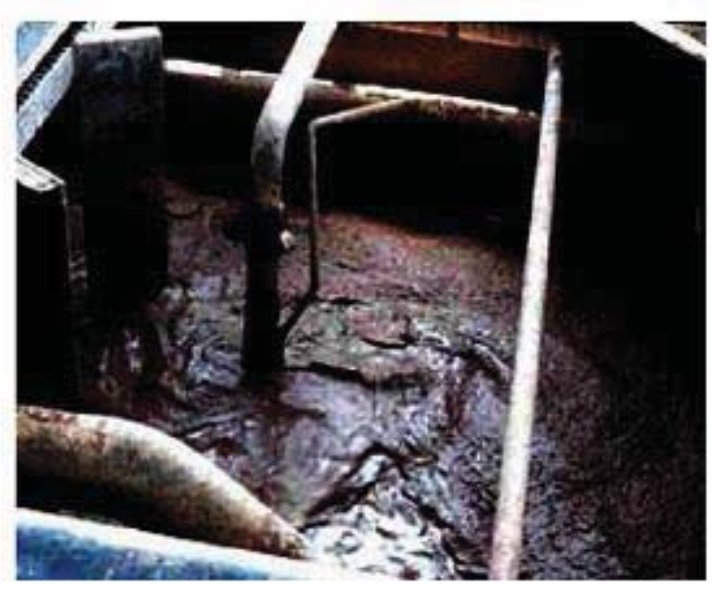

Fig. (2) Mud pit system (4)

4-Sack room: Gardner [6] reported that although base oil muds have attracted the biggest attention, workers are potentially exposed to a range of particulates, during powder handling of various additives especially barium sulphate in the sack room. The handling of these various powdered products can cause the exposure of mud engineers and other operators in the sack room to both skin contact and inhalation see Figure (3) (7).

5-Laundry services: Ineffective cleaning of personal protective equipment may leave residues of drilling fluids on the clothes which may be exposed to the skin. Cauchi[8] reported that detergent used by the rig laundry service may not be efficient or adapted to remove Oil Base Mud (OBM) or Non-Aqueous Drilling Fluid (NADFs) derivatives from the protective clothing, resulting in chemical accumulation into the clothing fibers.

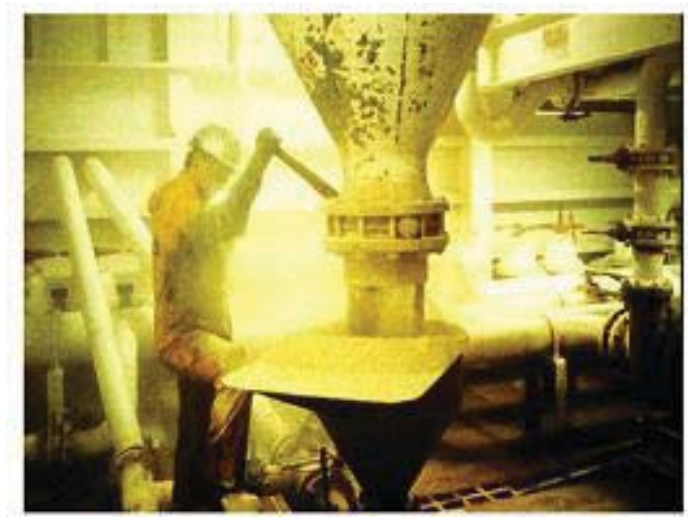

Fig.(3) Additive mixing at sack room (7) 


\section{Health effects associated with drilling fluids}

The risk of adverse health effects from drilling fluids is determined by the hazardous components of the fluids, additives and by human exposure to those components. Skin irritation and contact dermatitis are the most common health effects observed from drilling fluids exposure in human beings, with headache, nausea, eye irritation, and coughing seen less frequently. The effects are caused by the physico-chemical properties of the drilling fluid as well as the inherent properties of drilling fluid additives, and are dependent on the route of exposure such as dermal, inhalation, oral and others. These effects are:-

\section{1-Inhalation:}

Drilling fluids are often circulated in an open system at elevated temperatures with agitation that can result in a combination of vapors, aerosol and/or dust above the mud pit. In the case of water-based fluids the vapors comprise steam and dissolved additives. In the case of nonaqueous drilling fluids the vapors may consist of the low boiling-point fraction of hydrocarbons (paraffins, olefins, naphthenes and aromatics), and the mist contains droplets of the hydrocarbon fraction used. This hydrocarbon fraction may contain additives, sulphur, mono-aromatics and/or polycyclic aromatics. However, knowledge about the detailed composition and size of the aerosol droplets is limited. It should be noted that although the hydrocarbon fraction may contain negligible amounts of known hazardous constituents such as BTEX at low boiling point, these will evaporate at relatively higher rates potentially resulting in higher concentrations in the vapor phase than anticipated. Occupational exposure limits for several compounds may be specified in occupational health and safety regulations and exposure should not exceed these levels [4].

\section{2-Odour}

An issue indirectly related to health, but directly related to the working environment is the odour of drilling fluids. Some drilling fluids may have an objectionable odour caused by the main constituents or specific additives. During operations the drilling fluids may be contaminated with crude oil and drilling cuttings, which may change the odorous properties of the drilling fluid. Measurements of headspace volatiles during drilling operations have indicated the presence of dimethyl sulphide and isobutyraldehyde. Both compounds have a pungent odour and may create unpleasant working conditions (6). 


\section{$\underline{\text { 3-Neurotoxicity }}$}

Inhalation of high concentrations of hydrocarbons may result in hydrocarbon induced neurotoxicity, a non-specific effect resulting in headache, nausea, dizziness, fatigue, lack of coordination, problems with attention and memory, gait disturbances and narcosis. These symptoms are of a temporary nature and are only observed at extremely high concentrations (9). Exposure to high levels of hexane may result in peripheral nerve damage, an effect observed after prolonged exposure to high concentrations (10). Repeated dose studies in rats with a light naphtha stream containing up to 5 per cent n-hexane did not show neurotoxic effects (11).

\section{4-Pulmonary effects}

The most commonly observed symptoms in workers exposed to NAF and aqueous fluid aerosols are cough and phlegm $(11,12)$.Epidemiological studies of workers exposed to mist and vapor from mineral oils indicated increased prevalence of pulmonary fibrosis(5). More recent inhalation toxicology studies show that exposures to high concentrations of aerosols from mineral-based oils resulted mainly in concentration-related accumulation in the lung of alveolar macrophages laden with oil droplets (13). Inflammatory cells were observed with higher aerosol concentrations, consistent with the clinical literature from highly exposed workers. These pulmonary changes appeared to be a non-specific response to the presence of deposited aerosol and are not related to vapor exposure. The results on various petroleum mineral oils support the ACGIH® TLV of $5 \mathrm{mg} / \mathrm{m}^{3}$ for mineral-oil mist. It should be noted that extremely high concentrations of low viscosity hydrocarbon aerosols can either be aspirated, or be deposited in droplets in the lungs, causing chemical pneumonitis potentially resulting in pulmonary oedema, pulmonary fibrosis and, in occasional cases, death(14,15). In some cases, occupational exposure to drilling fluids is associated with respiratory irritation (16). It is likely that this is caused by additives in the drilling fluid and/or the physico-chemical properties as water-based drilling fluids have a typical $\mathrm{pH}$ of $8.0-10.5$. 


\section{$\underline{\text { 5-Dermal exposure }}$}

Most chemicals are readily absorbed through the skin and can cause other health effects and/or contribute to the dose absorbed by inhalation of the chemical from the air. When drilling fluids are circulated in an open system with agitation, there is a high likelihood of dermal exposure resulting in dermatitis and skin irritation. The potential dermal exposure is not limited to the hands and forearms, but extends to all parts of the body. Actual exposure depends on the drilling fluid system and the use of Personal Protection Equipment (PPE). Many studies indicate that absorption of chemicals through the skin can occur without being noticed by the worker. In many cases, skin is a more significant route of exposure than the lung (17).

\section{$\underline{\text { 6-Dermatitis and irritation }}$}

Skin contact with drilling fluids or mud can also cause inflammation of the skin, referred to as dermatitis. Signs and symptoms of dermatitis can include itching, redness, swelling, blisters, scaling, and other changes in the normal condition of the skin see Figure (4).

Petroleum hydrocarbons will remove natural fat from the skin, which results in drying and cracking. These conditions allow compounds to permeate through the skin leading to skin irritation and dermatitis. Some individuals may be especially susceptibility to these effects.

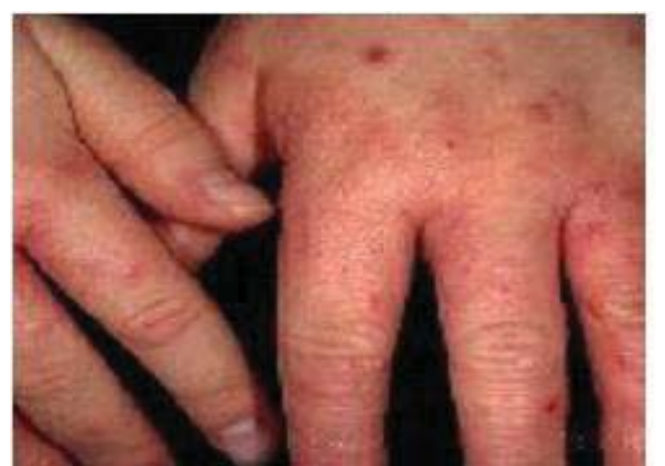

Fig. (4) Dermatitis of the hands (19)

Skin irritation can be petroleum hydrocarbons, specifically with aromatics and $\mathrm{C}_{8}-\mathrm{C}_{14}$ paraffins Petroleum streams containing these compounds, such as kerosene and diesel (gas oil), are clearly irritating to skin. This is suggested to become malignant caused by the paraffins, which do not readily penetrate the skin but are absorbed into the skin, hereby causing irritation (18). Linear alpha olefins and esters commonly used in drilling fluids are only slightly irritating to skin, whereas linear internal olefins are not irritating to skin.

In addition to the irritancy of the drilling fluid hydrocarbon constituents, several drilling fluid 
additives may have irritants, corrosive or sensitizing properties (8). For example calcium chloride has irritant properties and zinc bromide is corrosive whereas a polyamine emulsifier has been associated with sensitizing properties. Although water based fluids are not based on hydrocarbons, the additives in the fluid may still cause irritation or dermatitis. Excessive exposure under conditions of poor personal hygiene may lead to oil acne and folliculitis. ATSDR (19) concluded the possibility that adverse haematological and immunological effects might occur following dermal exposure to benzene.

\section{7-Oral exposure}

Oral exposure negligible as compared to the other exposure routes such dermal, inhalation and others. Oral exposure may occur when hands are not well washed before they are used to handle things like cigarettes. Data for the oral route of exposure are less extensive.

The BTEXs cause neurological effects, generally central nervous system depression, by the oral route. Renal and hepatic effects are also seen with oral exposure to these compounds. The hepatic effects tend to be mild, including increased liver weight and cytochromes. Benzene causes haematological effects by the oral route that is similar to those seen from inhalation exposure (20).

Caustic soda is the famous alkaline material that is mostly used in Iraqi fields .It has a decomposing effect on proteins, which may gradually penetrate the deep tissues unless the adhered alkaline is completely removed, in particular if the eyes are exposed to an alkaline, since eye tissue is rapidly affected causing a lowering or loss the vision, great care should be taken.

Also the caustic soda can affect the tissues of skin if it repeatedly comes in contact with the skin, which may cause dermatitis or chronic eczema. Inhalations of caustic soda dust or mist causes various degree of injury in the respiratory tract thus, the allowable concentration of caustic soda dust or mist in the air in a working area is specified as $2 \mathrm{mg} / \mathrm{m}^{3}(21)$.

\section{Other routes or combined routes of exposure}

A more likely scenario is drilling fluid coming into contact with the eyes. Hydrocarbon compounds of Groups I, II and III are not, or are slightly, irritating to the eye. However, specific additives in both aqueous and non-aqueous drilling fluids may be irritating or corrosive to eyes. On occasions, if drilling fluid or base fluid is under high pressure, fluid may be injected through the skin. As drilling fluids are generally of low systemic toxicity, the main effect expected is skin irritation (1). 


\section{$\underline{\text { 1-Reprotoxicity }}$}

Compounds associated with reprotoxicity are n-hexane and toluene. These compounds may be present in small quantities in Group II drilling fluids and in larger quantities in Group I fluids. However, a study involving 1269 men employed as offshore mechanics, offshore operators and offshore drilling personnel showed that paternal exposure to hydrocarbons in the occupations studied did not seem to have a major influence on time to conception or the incidence of spontaneous abortion among the wives of the men exposed to oil products (22). The olefins, esters and Paraffins commonly used in drilling fluids (Group III, negligible-aromatic content fluids) do not affect fertility nor cause developmental toxicity in animals.

\section{2-Particle size as an influencing factor}

Particle size is a critical influencing factor when it comes to health effects. Particle size can influence aerodynamic behaviors resulting in varying degrees of penetration and differing areas of deposition within the respiratory system (1).

\section{Challenges in setting drilling fluid exposure standards}

The health exposure standard of drilling fluid during oil and gas operations has always not be given the same attention or concern as its effects and risk management guidelines due to the following challenges: (4)

A- Drilling fluids are complex mixtures of variable composition

B- It is unclear about the longer term of health effect

C- There is no scientific basis on which to set health exposure limit

D- Exposure must be made up of all pertinent fractions such aerosol, vapour, etc., and all variation in composition

E- Exposure should reflect the level that can be achieved using good Practices.

\section{Exposure indicators}

In spite of the challenges of setting health exposure standards of drilling fluid exposure to oil and gas workers, Agency for Toxic Substances and Disease Registry (ATSDR) has researched into the BTEXs which are released as a result of drilling fluids during agitation under high pressures and temperature. The study presents these findings by ATSDR as an Exposure 
Indicator or Lowest Observed Adverse Effect Level (LOAEL) for drilling fluid exposure to operators to reduce the dangers of abnormal drilling fluids exposure.

\section{Exposure monitoring}

Workplace monitoring to assess the level of exposure in the work area or to a particular individual is a critical aspect of the risk management process and should be carried out regularly to assess the effectiveness of the controls in place and drive improvements. This monitoring includes:-

\section{1-Air monitoring}

Monitoring for dust, aerosol and vapor is a good way to accurately assess the level of drilling fluid component products present in the working atmosphere. The methods that need to be used to collect samples will vary with the chemical constituents of the drilling fluid systems in use and the duration of the sample. Common methods include:

A- Colorimetric detector tubes.

B- Passive and active adsorption samplers.

C-Filters.

D- Direct reading instruments.

E-Adsorption methods.

\section{2-Skin monitoring}

A common and effective approach to personal monitoring is skin monitoring. Methods of skin monitoring include:

A-Passive dermal monitoring.

B-Visual examination.

C- Trans-epidermal water loss.

D- Skin moisture level measurement.

\section{3-Workplace health monitoring}

Workplace health monitoring is a process designed to systematically detect and assess the early signs of adverse health effects on workers exposed to certain health hazards. Methods can be simple or more complex depending on the risks to workers from the job hazards and the substance, for example: 
A- Monitoring for signs of skin irritation when a worker is potentially exposed to a substance that can cause dermatitis or sensitization;

B- Medical surveillance including biological monitoring to check for the presence of toxins in the body, e.g. testing blood or urine for benzene or heavy metals. Where health surveillance information such as lung function test data is documented, records may have to be maintained for a minimum number of years if specified by legislation. In the absence of legislation, OGP/IPIECA suggests maintaining health records for a minimum of 40 years after the individual leaves employment.

\section{Risk management}

The best way to minimize occupational exposure to hazardous substances is through the adoption of risk management principles, which are the key to identifying successful workplace HSE controls.

The risk management process is an iterative process of continuous improvement and should continue throughout the lifecycle of the drilling operation. In order to identify the potential hazards it is imperative that persons with the responsibility, for the design and selection of drilling fluid systems make information regarding all the constituents of those systems available to those responsible for the risk management process(1).

\section{Hierarchy of risk controls}

At each stage of a drilling operation, if hazardous components of drilling fluids have been identified, together with a risk of exposure, the following hierarchy of controls should be considered:

1- Elimination.

2- Substitution.

3- Engineering controls.

4- Administrative controls (hygiene measures, working hours, Awareness and training).

5- Personal protective equipment. 


\section{1-Elimination}

A goal of all operations should be to avoid the use of hazardous substances, and to avoid procedures which may cause exposure. Various brands of additives and chemical products may be at hand for personal preference reasons or as recommended by a particular manufacturer in cases where an alternative common additive could be used. Numerous chemicals with identical properties and functions may therefore be available on site, which may be unnecessary and could impede risk management. Every operation should strive to reduce the number of chemicals being used to an absolute minimum (1).

\section{2-Substitution}

The hazard presented by a drilling fluid not only depends on the main constituent but also on the additives used. The primary observed effect after repeated exposure to drilling fluid is dermal irritation and dermatitis. Dermal irritation may be caused by $\mathrm{C}_{9}-\mathrm{C}_{14}$ Paraffin and aromatic hydrocarbons, as well as by some additives. Use of an aqueous drilling fluid or a non-aqueous drilling fluid based on Group III hydrocarbons (such as esters, alpha olefins or linear internal olefins) may decrease the irritation hazard. Drilling fluids with a high aromatic content may contain minimal amounts of benzene and a significant level of PAH, and may form a carcinogenic hazard. In addition, diesel-based drilling fluids may form a carcinogenic hazard due to chronic skin irritation. Using aqueous drilling fluids or fluids with low aromatic content will decrease the carcinogenic hazard (4).

\section{3-Engineering controls}

Ideally the design of the workplace will incorporate the engineering controls required to provide a workplace which minimizes exposure of hazardous substances to the workforce. Certain older rigs cannot always accommodate the larger ventilation systems or modified flow lines that serve as engineering controls to minimize personnel exposure to certain drilling fluid systems. The ability of the rig to accommodate, or be modified to accommodate, the engineering controls needed to reduce personnel exposure to acceptable limits should be considered in the contracting process. Over recent years many new technologies have been developed to address inferior work environment conditions. Some examples are given below. 


\section{Managed pressure drilling (MPD) and under-balanced drilling (UBD)}

Both MPD and UBD practices require that bell nipple areas and flow lines to the shakers be enclosed and that they are able to tolerate greater than atmospheric pressures. These practices ensure that gases, vapors and condensation issuing from the drilling fluid circulated from the well bore are contained. Such practices are not common to all drilling operations but mainly used when these specific drilling techniques are employed. Shale-shaker ventilation canopies while improvements and experience with effective ventilation technologies are being realized, ventilation canopies enclosing shakers are being used more often. Bulk handling and enclosed mix systems more modern facilities enable powdered products to be handled mechanically even to the point of removing and disposing of the packaging. Liquid additives can be pumped into the mixing system instead of manually poured. Alternatively, products and additives can be handled in bulk form from pre-loaded containers and added to the drilling fluid system from a remotely operated control zone.

Use of sensors in closed drilling fluid tanks has allowed drilling-fluid tanks to be completely enclosed, with control panels used to monitor tank levels (rather than visual inspection). This reduces the emission of gases, vapors and condensate to the work environment.

Introduction of real-time measurements Automatic sampling and/or testing devices can reduce exposure by avoiding the need to sample drilling fluids from open hatches/open tanks (1).

\section{$\underline{\text { 4-Administrative controls (1) }}$}

\section{A-Hygiene measures}

A-1 Laundry practices

Protective clothing as well as skin becomes contaminated by chemicals, and they are essential that these should be washed frequently. One of the most common sources of skin irritation at the well site has been due to the ineffective washing of coveralls and safety clothing. If not laundered properly, work clothing will retain fluid residue that can cause skin irritation when it is worn at the next time. The following procedures are recommended when washing clothing soiled with NAFs:

1-Do not overloads washers.

2- Designate one washer for drilling-fluid saturated clothing. Clothing that is not soiled with NAF fluid should always be washed in a separate washer.

3- When washing contaminated clothes, run the clothes through at least two wash cycles using 
hot water and detergent. Additional cycles may be needed if the clothing is extremely soiled with drilling fluid.

4- If it is not possible or practical to wash repeatedly, pre-soak the contaminated clothing in a laundry detergent solution for one to two hours before laundering.

\section{A-2 Washing facilities}

Removing all dirt and contaminants from the skin at the end of a day and during work breaks is extremely important, requiring the provision of adequate washing facilities. These include, as a minimum, an adequate supply of hot and cold running water, nail brushes and clean towels.

Rinsing in warm (not hot) running water and complete drying of the skin will help to reduce further the incidence of dermatitis; clean towels are preferable to air driers because the latter can de-fat the skin, and the time taken to dry the skin often leads to them not being properly used. The skin should be properly dried to avoid the risk of chapping, particularly during cold weather. Clean towels should therefore be available at all times; dirty towels mean exposing the skin to more dirt and bacteria, and to the risk of infection. The washing water available on a rig-site can be variable, with the hardness and $\mathrm{pH}$ being dependent on the source of the water; these factors can also contribute to a general drying of the skin.

\section{A-3 Skin cleansing}

Washing with soap and water is the most effective way of removing dirt and grime, provided the skin is not heavily soiled. However, choice of the correct soap is important: a quality soap that gives a good lather with a particular water supply will provide safe and often adequate cleansing. The use of solvents and abrasives should be avoided. They tend to remove too much of the skin's natural grease, making it more vulnerable to other irritants, and can also cause dermatitis or other harm to the skin. Special skin cleansers are now widely available which allow safe and effective removal of dirt and irritants without upsetting the structure of the skin or its functions. For external sites where no piped water supply is available; there are special waterless skin cleansers and cleansing wipes. 


\section{A-4 Barrier cream}

General-purpose barrier creams are designed to protect against either water-soluble or solvent-soluble irritants. Their efficiency is limited and they cannot in any way be regarded as a substitute for good occupational hygiene practice, good skin cleansing and reconditioning practices. The main advantage of a barrier cream is that it facilitates the removal of contamination from skin. The cream should be properly applied to the skin surface in hygienic conditions. Even when properly applied, its effectiveness will reduce after only 2 to 3 hours and it should be re-applied; the cream should also be re-applied after washing the hands. Barrier creams offer no effective protection for a person who has already been sensitized, because in such a case the person would react to very low amounts of the sensitizer. Some people can react to the ingredients of barrier creams and the use of these creams, especially under protective impermeable gloves, can in itself cause skin irritation. Barrier creams should be provided in hygienic wall-mounted dispensers at each changing area, with an alternative for use by personnel who may experience a reaction to a particular brand.

\section{A-5 Skin reconditioning}

The use of a reconditioning cream is often the most important stage in skin care, and generally the one which is not performed at all. The use of a conditioning cream at the end of the working day helps to replace the natural fats and oils which have been stripped from the skin by contact with chemicals and frequent cleansing. The reconditioning cream also helps to replace damaged skin cells and minimize infection of any cuts, scratches or abrasions of the skin. Reconditioning cream should be applied to clean; dry skin in the same way as barrier cream. The installation of specially designed dispensers for use with liquid and gel skin cleansers and creams is strongly recommended. Such dispensers reduce to a minimum the risk of cross- infection and cream contamination that can occur if a number of people use the material from an open or communal container. Such dispensers should also be used in shower cubicles.

\section{B-Working hours}

A useful administrative control is to modify shift patterns and rotate jobs, thus limiting hours of exposure to potential hazards. 


\section{C-Awareness and training}

Awareness and training on the hazardous materials, potential exposures and their

Health effects are critical. The following steps should be conducted:-

1- Material Safety Data Sheets should be provided for drilling fluid systems, components and additives.

2- Material Safety Data Sheets for all drilling fluid system components and additives should be reviewed with personnel prior to working with these chemicals.

3- Personnel should be trained in the recommended handling procedures; the selection, maintenance and storage of appropriate PPE; rig health and safety equipment; and procedures for reporting occupational illnesses such as skin irritations and for reporting to operation supervisors the drilling practices that may be increasing exposure levels.

4- Medical personnel should be selected giving consideration to their experience and expertise in the diagnosis and initial treatment of acute occupational illnesses related to the handling of these chemicals. Emergency situations, such as a major spillage or release, should be considered when designing administrative.

\section{D-Personal protective equipment}

One of the most significant factors in effective (PPE) usage is personal comfort.People will not wear personal protective equipment properly if it is uncomfortable or if their movement is restricted. The use of protective clothing is advised to prevent direct contact with chemicals. PPE may include chemical splash goggles, appropriate chemical-resistant impermeable gloves, rubber boots, coveralls, and for roughnecks, slicker suits, when performing tasks such as tripping wet pipe or in work environments that are heavily contaminated with oil mist. Wearing chemical resistant gloves and clothing is usually the primary method used to prevent skin exposure to hazardous chemicals in the workplace. Glove and protective clothing selection is usually based on manufacturer's laboratory-generated chemical permeation data. This is unlikely to reflect actual conditions in the workplace, e.g. elevated temperatures, flexing, pressure and product variation between suppliers. To minimize worker exposure to heat stress in areas where the ambient temperature is very high, disposable chemical- resistant coveralls can be utilized instead of slicker suits. Regular changes of these disposable suits and/or chemical resistant gloves may be required depending on breakthrough time and level of contamination. When working $\backslash$ with 
drilling fluids, if ventilation is not adequate it is recommended that goggles and self-contained respirators are worn at all times. Respiratory protective equipment (RPE) is considered to be a last resort. RPE should only be considered when exposure cannot be adequately reduced by other means. It is vital that the RPE selected is adequate and suitable for the purpose. It should reduce exposure to as low as reasonably practicable, and in any case to below any applicable occupational exposure limit or other control limit. To make sure that the selected RPE provides adequate protection for individual wearers, fit testing of RPE including full-face masks, half-face masks and disposable masks is strongly recommended. This will help to ensure that inadequately fitting face masks are not selected. Combination filters with organic vapor cartridges should be used when performing activities where there is the potential for hydrocarbon exposure (1).

It is noted that for each company there is an observation checklist includes number of elements such as reaction of people ,PPE availability, Injury causes, tools , equipment, procedures and orderliness figure(5) this observation checklist is belong to Schlumberger company. 


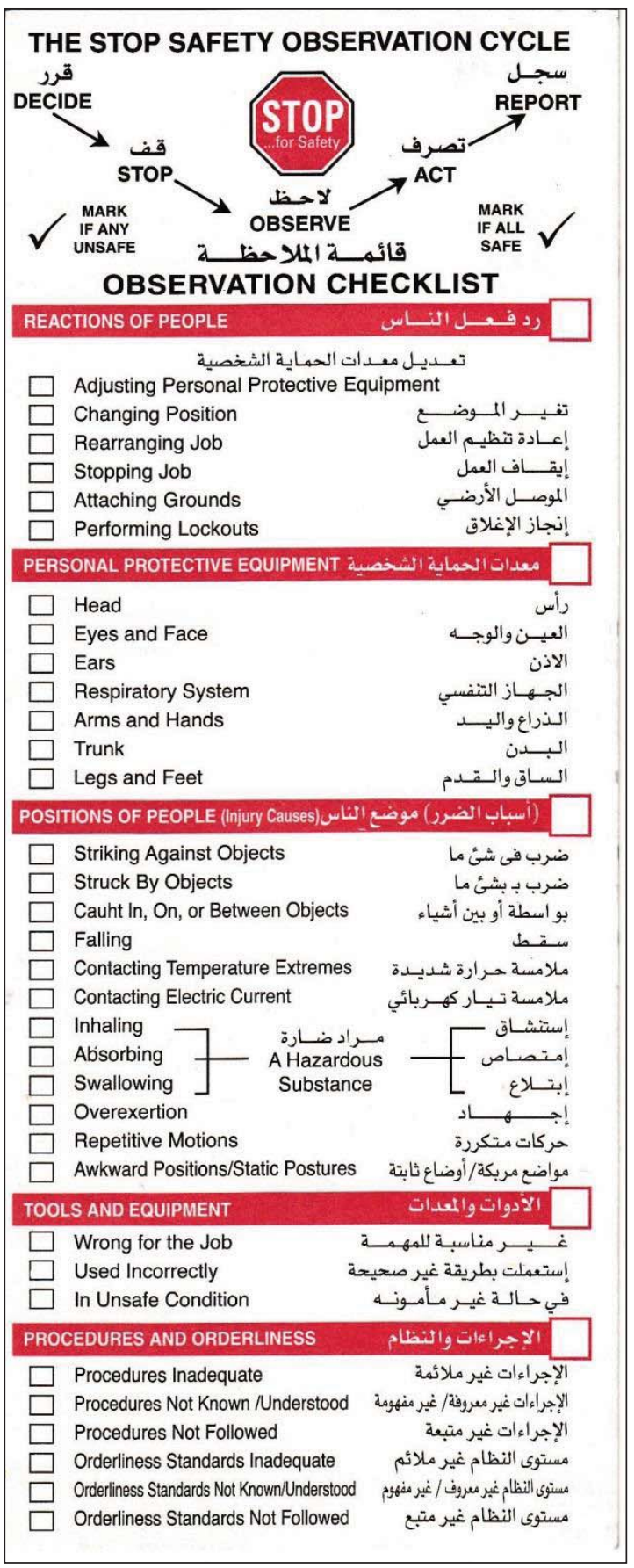

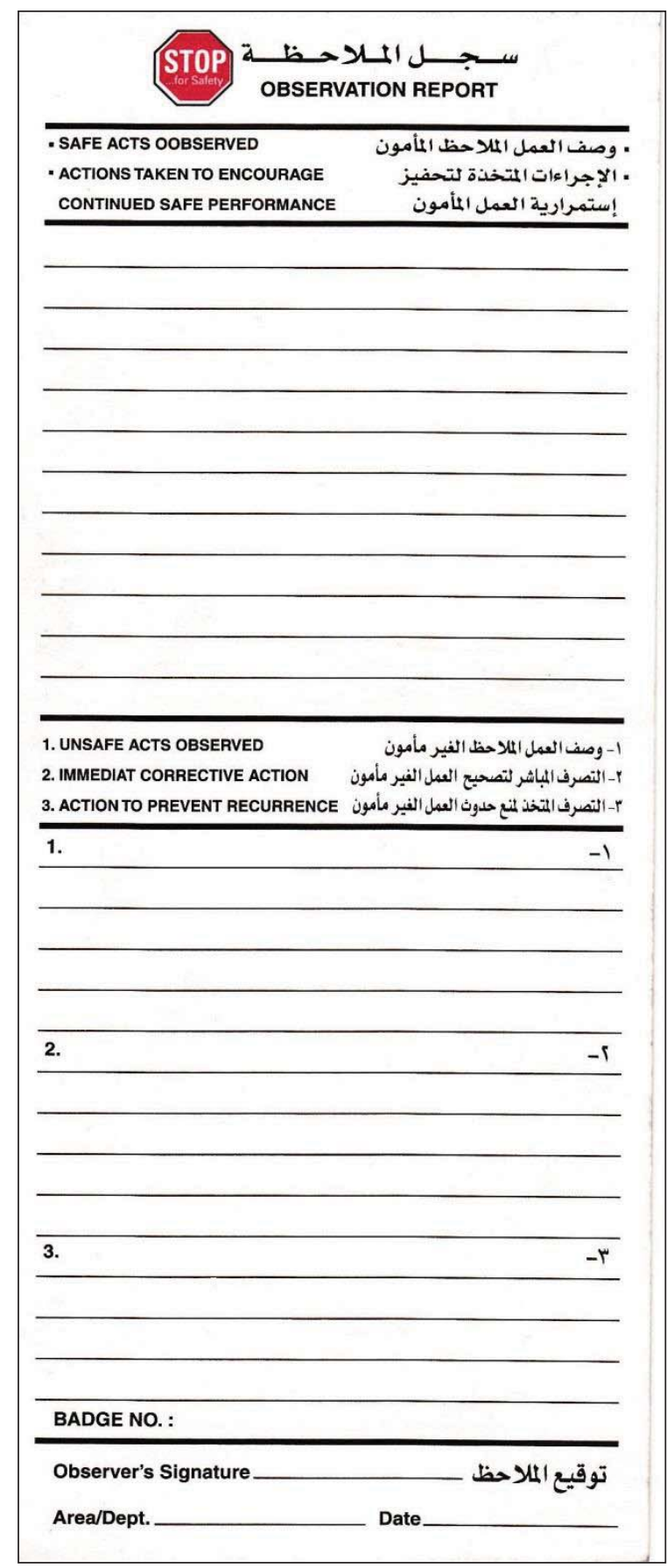

Fig. (5) Observation checklist. 


\section{The administrative processes adopted in our fields}

The questionnaire has been done on seven Iraqi fields (Nahran Omar, Nasiriya, Zubair, East Baghdad, North Rumaila, Humrain and Jambur). The obtained data from this questionnaire are tabulated in (table 1) and filled by the site engineers of those oil fields while attending developing courses held through January to July/2014 in Baghdad oil training institute/Iraqi drilling centre. This questionnaire aims to determine the administrative and protective processes

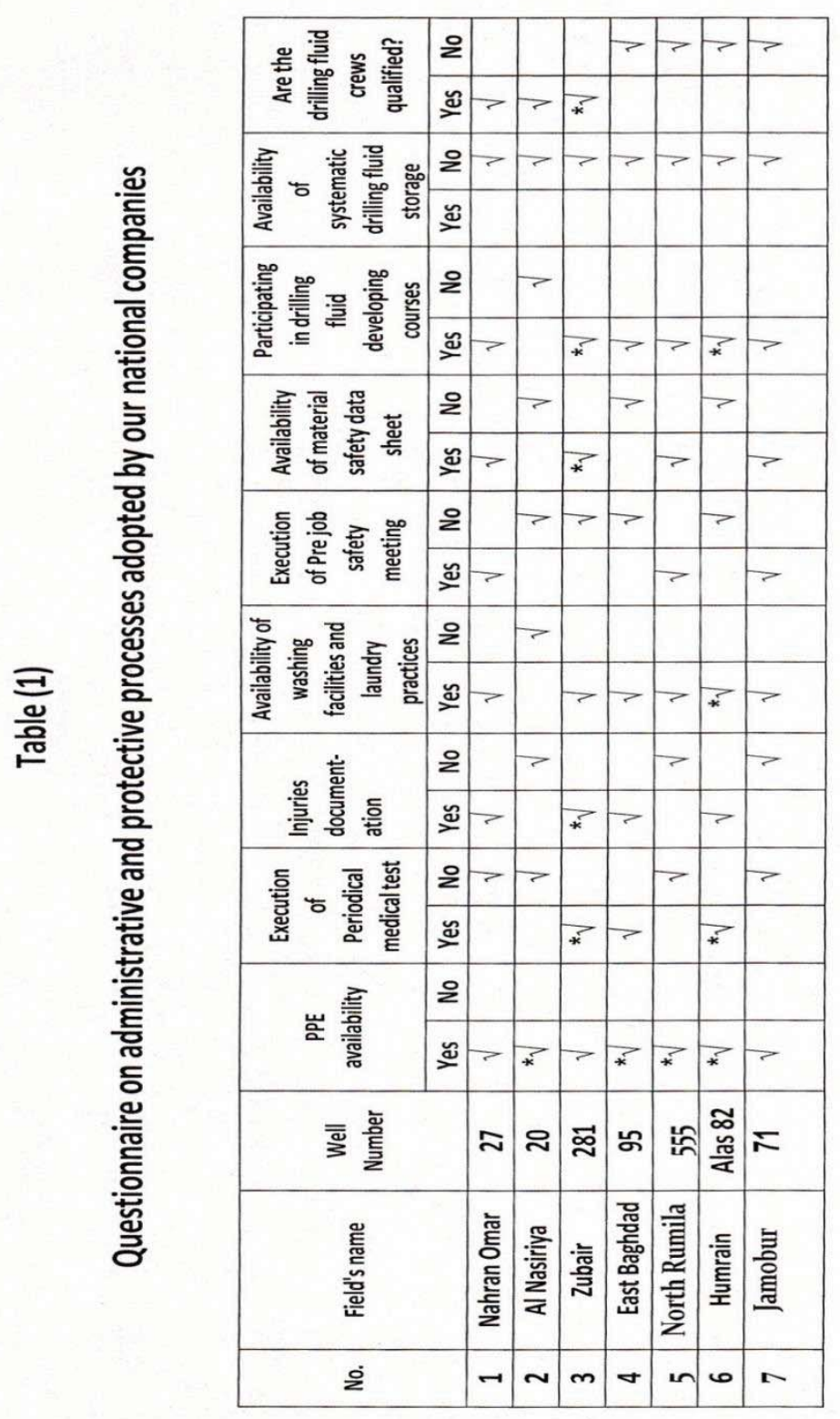


adopted by our national companies in order to minimize exposures to drilling fluids. According to the data obtained from the questionnaire we can see the followings:1-In Nasiriya, East Baghdad, North Rumaila and Humrain fields, most of PPE such as respirators, gloves and special suits are not available.

2-There is no clear medical test schedule found in Nahran Omar, Nasiriya, North Rumaila, and Jambur fields.

These tests are conducted in formal government hospitals by special committee specialized in dermal and chest diseases only.

3-No MSDS for all drilling fluid materials are available in Nasiriya, East Baghdad and Humrain fields while such data for some drilling fluid materials are available in Zubair field.

4-Most of the drilling fluid workers are classified as casuals and are not qualified as indicated in East Baghdad, North Rumaila, Humrain and Jambur fields, while in Zubair field there are qualified and non-qualified workers.

5-In all selected fields; there is no systematic drilling fluid storage.

6-There is no hygiene and laundry facilities in Humrain field.

7-There is no documentation for worker injuries as indicated in Nasiriya and Jambur fields while the bone injuries are documented only in Zubair Field

8- Pre safety meeting for drilling fluid workers is not conducted in most fields such as Nasiriya ,Zubair ,East Baghdad and Humrain, there are no clear schedule plans to develop the drilling fluid crew as indicated in Zubair and Humrain fields.

\section{Conclusions}

1-This study reveals the major areas of drilling fluid exposure as setting of pipe at the drill floor, manual handling of sack at the sack room and other related issues as major areas of drilling fluid exposure. Findings also reveal that, the major health hazards such as dermatitis, body irritation, neurological effects etc. Hazards associated with drilling fluids exposure are mainly through inhalation, skin contact and oral exposure.

2- There are no clear, standard and unique administrative and protective processes

Adopted in our fields. 
3- The International Association of Oil \& Gas Producers (OGP) has published a guide for drilling personnel, managers and health professionals in the oil and gas industry titled "Drilling Fluids and Health Risk Management". This document is a useful reference guide for those planning operations, assessing worker hazards or developing an exposure control plan.

4- The broader solution to health exposure issues during drilling requires a comprehensive and collaborative approach that involves the producers, drilling contractors and drilling fluid suppliers. This approach includes the following elements:

- Fluid selection (responsibility of producer).

- Exposure control plans.

- Engineering controls at the mud tanks and shakers.

- Awareness and training on the all types of drilling fluids.

\section{$\underline{\text { Recommendations }}$}

1-It is recommend that Iraqi drilling company should evaluate the potential for worker exposure and take steps to eliminate or reduce the risks with consideration given to the following areas:-

- Ventilation to be reviewed where applicable to reduce the exposure to chemicals and contact with workers.

- Where possible reduce the amount of time that workers are required to work in areas where oil mist exists.

- Workers to wear appropriate PPE when required to work with oil based muds.

- Evaluate the current awareness tools and training programs to address the challenges related to chemical exposure.

2-Periodical meetings with drilling fluid workers should be conducted and the standard safety instruction should be followed.

3-Establishing a special committee under name of drilling fluid system developing. This committee studies the reliable ways leading to reduce the drilling fluid exposures through using modern techniques such as managed pressure drilling (MPD) and under-balanced drilling (UBD) and develops some of the surface equipment such as using protective canopies for shale shakers, for the return flow or for the mud tank depending on the drilling fluid type and work regulations. 
4-Applying periodical medical test for our drilling fluid workers according to clear and standard schedule, treat the drilling fluid injuries and record the injury type in special document which can be used as reference document and apply the suitable recommendations. The medical test should include various medical fields such as dermal, chest, neuric, eyes, ear, noise and throat. 5-Developing our workers by evaluating their awareness with chemicals and equipment, executing developing courses in this field and activating the job description for all workers.

6-Developing a special observation report to evaluate work processes according to the health, safety and environment as in the foreign companies.

\section{Abbreviations}

BTEX: Benzene, toluene, ethyl benzene and xylenes.

HSE: Health, safety and environment.

$\mathrm{mg} / \mathrm{m}^{3}:$ milligrams per cubic meter.

NAF: Non-aqueous fluids.

NADFs: Non aqueous drilling fluids.

OBM: Oil base mud.

UBD: Under balanced drilling.

MPD: Managed pressure drilling.

OGP: International Association of Oil \& Gas Producers.

PPE: Personal protective equipment.

ATSDR: Agency for Toxic Substances and Disease Registry.

WBF: Water-based fluid.

IPIECA: International Petroleum Industry Environmental Conservation Association.

LOAEL: Lowest Observed Adverse Effect Level.

RPE: Respiratory protective equipment.

PAH: polycyclic aromatic hydrocarbon.

ACGIH $®$ : American Conference of Governmental Industrial Hygienists.

TLV: Threshold limits value. 


\section{References}

1. Drilling fluids and health risk management, a guide for drilling personnel, managers and health professionals in the oil and gas industry, International Petroleum Industry Environmental Conservation Association (IPIECA,) International Association of Oil \& Gas Producers (OGP), United Kingdom, (2009).

2. OGP, Environmental aspects of the use and disposal of non-aqueous drilling fluids associated with offshore oil and gas operations. International Association of Oil and Gas Producers (OGP),No. 342.( 2003).

3. Neff, J.M., S. McKelvie and R.C. Ayers,.Environmental impacts of synthetic based drilling fluids. Report prepared for MMS by Robert Ayers, and Associates, Inc., U.S. Department of the Interior,Minerals Management Service, Gulf of Mexico OCS Region, New Orleans, LA. OCS Study MM S, pp:1-10.(2000).

4. Effects of Drilling Fluid Exposure to Oil and Gas Workers Presented with Major Areas of Exposure and Exposure Indicators E. Broni- Bediako and R. Amorin Petroleum Engineering Department, University of Mines and Technology, Tarkwa, Ghana, December, (2010).

5. James, R., A. Nistov, C. Smulders, K. W alker, T. Schei,N. LeBlond, M. Sopko and T. Fonneland,. Occupational Exposure Hazards Related to the use of Drilling Fluids Presented with Remedial Risk Management Guidelines, SPE Asia Pacific Health, Safety, Security and Environmental Conference and Exhibition, Bangkok, Thailand, SPE 108514, pp:1-10..(2007).

6. Gardner, R., Overview and characteristics of some occupational exposures and health risks on offshore oil and gas installations. Ann. Occup. Hyg., 47(3):201-210.(2003).

7. Saleem, A. and L. Ross,. Offshore Chemical Essentials. Retrieved.From: http://stepchangeinsafety. net/stepchange/News/StreamContentPart.aspxID=4031, Power Point Presentation, pp: 1-26. (Accessed on: September 10). (2009).

8- Cauchi, G.,. Skin rashes with oil-base mud derivatives', safety, and environment in oil and gas exploration and production, calgary. SPE International Conference on Health, SPE 86865, pp:12.(2004).

9. Douglas, J.F., McKee, R.H., Cagen, S.Z., Schmitt, S.L., Beatty, P.W., Swanson, M.S., Schreiner, C.A., Ulrich, C.E. and Cockrell, B.Y. A Neurotoxicity Assessment of High Flash Aromatic Naphtha. Toxicol Ind Health 9 1047-1058. (1993).

10. Huang, J., Kato, K., Shibata, E., Sugimura, K., Hisanaga, N., Ono, Y. and Takeuchi, Y. Effects of Chronic n- Hexane Exposure on Nervous System-Specific and Muscle-Specific Proteins. Arch Toxicol 63 .381-385. (1989). 
11. Ameille, J.,Wild, P., Choudat, D., Ohl, G.,Vaucouleur, J.F., Chanut, J.C. and Brochard, P. Respiratory Symptoms, Ventilatory Impairment, and Bronchial Reactivity in Oil Mist-Exposed Automobile Workers.American Journal of Industrial Medicine 27 247-256. (1995).

12. Greaves, I.A., Eisen, E.A., Smith, T.J., Pothier, L.J., Kriebel, D.,Woskie, S.R., Kennedy, S.M., Shalat, S. and Monson, R.R. Respiratory Health of Automobile Workers Exposed to Metal-Working Fluid Aerosols:Respiratory Symptoms. American Journal of Industrial Medicine32 450-459. (1997).

13. Dalbey,W.E. and Biles, R.W. Respiratory Toxicology of Mineral Oils in Laboratory Animals. Appl Occup Environ Hyg 18 (2003) 921-929.(2003).

14.Proudfit, J.P., Van Ordstrand, H.S., and Miller, C.W.Chronic Lipid Pneumonia Following OccupationalExposure. Arch Industrial Hygiene Occupation Med 1105-111. (1950).

15. Foe, R.B. and Bigham, R.S., Jr. Lipid Pneumonia Following Occupational Exposure to Oil Spray. Journal of the American Medical Association 15533-34.(1954).

16. Davidson, R.G., Evans, M.J., Hamlin, J.W. and Saunders,K.J. Occupational Hygiene Aspects of the Use of Oil-Based Drilling Fluids. Ann Occup Hyg 32 325-332. (1988).

17. OSHA,Safety and Health Topics, Dermal Exposure, United States Departments of labor, Occupational Safety and Health Administration. Retrieved from: http://www.osha.gov/SLTC/dermalexposure/index.html, (Accessed on: October 28).( 2009).

18. Anonymous, Retrieved from: http://dermnetnz.org/ dermatitis/img/hnd-dermatitis/index.html (Accessed on: August 27).(2009).

19- ATSDR, Toxicological Profile for Benzene,Agency for Toxic Substances and Disease Registry, Public Health Service, U .S.Department of Health and Human Services, Atlanta, GA., pp: 11262.( 1997).

20. ATSDR, a. Toxicological Profile for Total Petroleum Hydrocarbons (TPH), Agency for Toxic Substances and Disease Registry, Public Health Service, U.S. Department of Health and Human Services, Atlanta, GA., 4: 102-114.(1999).

21. Japan soda industry. Safe handling of caustic soda (sodium hydroxide). Permanent committee on technology and safety, revised edition, Nov.20, (2006).

22. Bull, N., Rise,T. and Moen, B.E. Influence of Paternal Exposure to Oil and Oil Products on Time to Pregnancy and Spontaneous Abortions.Occup Med (Lond). 49 371-76. (1999). 